\title{
SHAPING SOUTHEAST ASIAN STUDIES FOR THE FUTURE
}

\author{
${ }^{1}$ Hanafi Hussin* \& ${ }^{2}$ Mala Rajo Sathian** \\ (*First author, ${ }^{* *}$ Corresponding author) \\ ${ }^{1,2}$ Department of Southeast Asian Studies, \\ Faculty of Arts and Social Sciences \\ ${ }^{1}$ Institute of Ocean and Earth Sciences (IOES) \\ University of Malaya \\ (hanafih@um.edu.my, malarajo@um.edu.my)
}

\begin{abstract}
Southeast Asian Studies is an important educational and scholarly research platform to understand the different aspects of the Southeast Asian region. Western scholars have contributed significant research produced under the programmes; local researchers have added their voice to the study of the region. However, Andaya (2017) suggested that the field of SEAS should be mindful of its relevance to the current generation, and its development and progress should be in-line with the changes in contemporary scholarly needs of Southeast Asia. She asserted that the world and Southeast Asia have been transformed. However, the research and teaching approach and the scope of the programme remains unchanged. A critical review and rethink of the field of study in the region is urgent. SEAS needs to be reshaped to be relevant and progressive to suit the current scenario. This paper will examine whether SEAS could move away from its conventional teaching and research approach, and undergo a rebranding exercise that will be compatible to meet the demands of the changing world. The paper will also allude to potential challenges in reshaping the form and content of SEAS in the region.
\end{abstract}

Keyword: Southeast Asian Studies, SEAS, teaching, research, publication, rebranding, reshaping, challenges 